\title{
Narrativas de futuros professores dos anos iniciais: um olhar para memórias sobre a matemática e contribuições de uma disciplina na formação inicial
}

Narratives of future teachers of early years: a look at memories about mathematics and contributions of a discipline in the initial teacher education

\author{
Wallace Alves Cabral ${ }^{1}$ \\ Reginaldo Fernando Carneiro ${ }^{2}$
}

\section{Resumo}

A formação de professores que ensinam matemática nos anos iniciais tem sido temática frequente nas pesquisas em Educação Matemática a partir de diferentes perspectivas teóricas e metodológicas. Assim, temos como objetivos, neste artigo, identificar algumas memórias dos estudantes de um curso de Pedagogia relacionadas à matemática na Educação Básica, bem como refletir sobre possíveis contribuições das disciplinas de matemática desse curso para pensar o ensino e a aprendizagem. Para tanto, analisamos duas narrativas produzidas por futuros professores dos anos iniciais que cursaram essas disciplinas. Em uma das narrativas eles abordaram memórias relacionadas à matemática durante sua trajetória escolar e em outra discutiram o que pensavam sobre a matemática após as vivências na disciplina I. A análise dos dados evidenciou que, de modo geral, os estudantes são fortemente marcados pelas experiências negativas que tiveram durante a Educação Básica. Além disso, em seus discursos, percebemos influências das atividades e discussões que ocorreram nessa disciplina, o que permitiu para muitos lançar um novo olhar para a matemática.

Palavras-chave: Narrativas. Formação de professores dos anos iniciais. Matemática.

\footnotetext{
${ }^{1}$ Doutorando em Educação e Licenciado em Química pela Universidade Federal de Juiz de Fora UFJF. Professor da Faculdade de Ciências Exatas e Tecnologia da Universidade Federal da Grande Dourados - UFGD.

${ }^{2}$ Doutor em Educação e Licenciando em Matemática pela Universidade Federal de São Carlos UFSCar. Professor da Faculdade de Educação e dos Programas de Pós-Graduação em Educação e em Educação Matemática da Universidade Federal de Juiz de Fora - UFJF.
} 


\section{Abstract}

The teacher education who teaches mathematics in the early years has been frequently thematic of research in Mathematics Education with different theoretical and methodological perspectives. Thus, the aims of this article are identify some memories of students of a Pedagogy course related to mathematics in Basic Education, as well as to reflect on possible contributions of the mathematics subjects of this course to think about the teaching and the learning. To do so, we have analyzed two written narratives by future teachers of the early years that coursed these disciplines. In one of the narratives they have written about memories related to mathematics during their school trajectory and in the other they have discussed what they thought about mathematics after the experiences in the subject I. The data analysis showed that, in general, the students are strongly marked by negative experiences they had during the Basic Education. In addition, in their speeches, we realized influences of activities and discussions that occurred in this subject, which allowed for many students, launch a new look to the mathematics.

Keywords: Narratives. Teacher education of the early years. Mathematics.

\section{Introdução}

Este artigo tem como objetivos identificar algumas memórias dos estudantes de um curso de Pedagogia relacionadas à matemática na Educação Básica e refletir sobre possíveis contribuições das disciplinas de matemática desse curso para pensar o ensino e a aprendizagem.

Para isso, analisamos duas narrativas escritas por futuros professores dos anos iniciais que cursaram as disciplinas de matemática de um curso de Pedagogia de uma universidade federal de Minas Gerais. Em uma das narrativas eles abordaram memórias relacionadas à matemática enquanto alunos da Educação Básica e em outra discutiram o que pensavam sobre a matemática após as vivências na disciplina I.

Constam na grade curricular desse curso de Pedagogia duas disciplinas obrigatórias relacionadas à matemática que são oferecidas no $4^{\circ}$ e $5^{\circ}$ períodos com carga horária de 60 horas cada uma. Para distinguir essas disciplinas as denominaremos de disciplina I e disciplina II. Nelas foram abordados e discutidos conceitos e conteúdos matemáticos, aspectos metodológicos e também 
apresentados jogos e materiais manipuláveis que podem ser utilizados pelo professor em suas aulas.

Neste texto, apresentamos inicialmente o referencial teórico que embasa nossas discussões, em seguida, os caminhos da pesquisa em que trazemos aspectos da metodologia utilizada. Após, apresentamos e analisamos os dados presentes nas duas narrativas e, por fim, tecemos algumas considerações.

\section{A formação matemática do professor dos anos iniciais}

A pesquisa sobre o professor que ensina matemática nos anos iniciais tem sido destaque das discussões educacionais, principalmente, no campo da Educação Matemática. Assim, muitos investigadores têm se debruçado sobre essa temática a partir de diferentes perspectivas teóricas e metodológicas. Para exemplificar, apresentamos a seguir alguns estudos que abordam essa formação do professor dos anos iniciais.

Segundo Nacarato, Mengali e Passos (2009), os professores dos anos iniciais têm, em sua formação, disciplinas com carga horária reduzida que enfatizam aspectos metodológicos em que não vivenciam os fundamentos da matemática e a prática da pesquisa em Educação Matemática.

Assim, a prática desses docentes reproduz a dos professores que eles tiveram em sua escolarização, que para essas autoras (2009), influenciam sobremaneira a formação da identidade docente e na constituição do modelo de aula. Com poucas exceções, esses professores tiveram, enquanto alunos, um ensino de matemática que enfatizou os números e as operações aritméticas a partir de aplicação mecânica de algoritmos e procedimentos.

Além disso, em relatos escritos, esses professores demonstram "trazer marcas profundas de sentimentos negativos em relação a essa disciplina, as quais implicam, muitas vezes, bloqueios para aprender e para ensinar" (2009, p. 23). Uma futura professora, por exemplo, desenhou uma bomba, explicando que sempre levava bomba nas avaliações escolares em matemática. Outra comentou 
que não conseguia compreender os conteúdos matemáticos e, por isso, ficou muito frustrada (NACARATO; MENGALI; PASSOS, 2009).

Nessa perspectiva as frustrações, as inseguranças e os medos em relação à matemática podem ter repercussões na configuração de suas aulas. $\mathrm{O}$ desafio da formação inicial está em

criar contextos em que as crenças que essas professoras foram construindo ao longo da escolarização possam ser problematizadas e colocadas em reflexão, mas, ao mesmo tempo, que possam tomar contato com os fundamentos da matemática de forma integrada às questões pedagógicas (NACARATO; MENGALI; PASSOS, 2009, p. 37-38).

Contudo, ainda de acordo com essas autoras (2009, p. 32), a formação inicial deve proporcionar ao futuro professor "construir um currículo de matemática que transcenda o ensino de algoritmos e cálculos mecanizados, principalmente nos Anos Iniciais, onde está a base da alfabetização matemática". Dentro disso, é comum observar nas produções dos estudantes a repetição empírica, que segundo Orlandi (2012), refere-se à repetição mnemônica que é a do papagaio, que só repete.

Gomes (2006) também investigou a formação dos professores que ensinam matemática nos anos iniciais e identificou algumas dificuldades ao resolverem problemas de estrutura multiplicativa. Nesse estudo, buscou-se provocar desequilíbrios e desestabilizações nas crenças que poderiam influenciar a prática docente desses futuros professores.

Os resultados apontaram que os participantes da pesquisa conseguiram minimizar suas dificuldades e tomar consciência de suas limitações, possibilitando dar o primeiro passo no sentido da superação dos obstáculos. Segundo a pesquisadora (2006, p. 143), foi possível perceber um "sentimento de alívio, pela consciência de que todo este medo surgiu em decorrência do desconhecimento e pela falta de domínio dos conceitos básicos. Mais interessante foi notar a participação, o envolvimento cada dia maior, a sede em reconstruir os conceitos que permearam suas vidas por tanto tempo" (grifo da autora). 
Em outro estudo, Nacarato (2010) apontou que muitas das dificuldades dos futuros professores dos anos iniciais em Pedagogia surgem das vivências enquanto estudantes da Educação Básica e dos bloqueios e conflitos relacionados a terem que ensinar matemática em sua profissão. Nesse contexto, a formação deve tentar romper com as crenças e os modelos de aula de matemática que vivenciaram nessa trajetória.

Para tanto, essa autora (2010) apresentou algumas discussões a partir de relatos autobiográficos e textos reflexivos escritos por alunas de curso de Pedagogia. Nesses textos são narrados conteúdos matemáticos que essas estudantes gostavam ou que não aprenderam e também acontecimentos sobre seus professores. Foram apresentadas lembranças sobre a aritmética e sobre a geometria, com menor ênfase nessa última, aspectos utilitários da matemática e questões que evidenciam que as reformas educacionais pouco influenciaram no ensino de matemática.

Lacerda (2011) pesquisou o perfil do aluno formado em um curso de Pedagogia e sua visão sobre a formação para ensinar matemática nos anos iniciais. A partir de um questionário, a autora verificou a relação de recém formados com as disciplinas de matemática do curso. Alguns dos participantes não lembravam-se ou lembravam-se apenas vagamente de como aprenderam matemática, evidenciando falta de entusiasmo e um indício do desconforto com relação à matemática. Muitos professores sentiam indisposição e mesmo aversão à matemática e indicaram que 0 curso de Pedagogia reafirmou esses sentimentos.

Os participantes também apontaram mudanças que proporiam na grade curricular do curso referente às disciplinas de matemática, propondo que o estágio fosse realizado em matemática, valorizando os conhecimentos relacionados às práticas. Propuseram ainda aumento das disciplinas de matemática do curso e modificações na forma como são ofertadas as disciplinas, sugerindo "mudanças na didática, na metodologia, nos conteúdos, troca dos 
professores e também recomendações de que fossem feitas propostas de inovação, de novas maneiras de ensinar Matemática" (LACERDA, 2011, p. 108).

Por fim, apresentamos o estudo de Carneiro (2015) que teve como objetivo discutir algumas contribuições das disciplinas de matemática de um curso de Pedagogia para a formação do professor dos anos iniciais do Ensino Fundamental. Nessa pesquisa foram analisadas seis narrativas escritas durante essas disciplinas relacionadas à matemática.

As análises das narrativas evidenciaram que a dinâmica das disciplinas, proporcionada pelo professor, em que estudantes realizavam uma atividade, apresentavam suas conclusões e as discutiam teoricamente, promoveu muitas indagações, reflexões e questionamentos e; possibilitou aos estudantes adquirir a consciência de que a forma como aprenderam matemática pode ter contribuído negativamente para a compreensão dos conceitos e conteúdos dos anos iniciais. Assim, os estudantes demonstraram preocupação com sua futura prática docente e indicaram o início de uma nova relação com a matemática. Ainda, foram discutidos conceitos e conteúdos que, via de regra, não são problematizados na formação inicial. Dessa forma, essas disciplinas de matemática buscaram formar o futuro professor da maneira como se espera que ele atue.

Compreendemos que o curso de formação inicial deve promover a problematização e levar os futuros professores a refletirem sobre suas experiências com relação à matemática enquanto estudantes, seus sentimentos, angústias e traumas, conceitos e conteúdos matemáticos e o ensino e a aprendizagem dessa disciplina, buscando romper com algumas concepções.

Para o referencial teórico e metodológico aqui adotado, a Análise do Discurso de Linha Francesa (AD), é a partir das histórias de leituras dos discentes que devemos iniciar o processo de construção do conhecimento. Desse modo, os estudantes terão maior facilidade em compreender um significado novo quando o reconhece por meio de suas próprias palavras relacionadas, tornando-se essencial conhecer as características e as relações de cada linguagem. 
Uma possibilidade para compreender e contribuir com essas histórias de leituras (ou memórias) consiste na utilização de narrativas, que neste estudo, possibilitou identificar algumas de suas memórias e as contribuições das disciplinas de matemática de um curso de Pedagogia.

A partir do exposto, passamos a apresentar e discutir alguns aspectos da metodologia da pesquisa.

\section{Caminhos da pesquisa}

Tivemos como objetivos, neste artigo, identificar algumas memórias dos estudantes de um curso de Pedagogia relacionadas à matemática na Educação Básica, bem como refletir sobre possíveis contribuições das disciplinas de matemática desse curso para pensar o ensino e a aprendizagem.

Para tanto, baseamo-nos na $A D$ que nos faz questionar a transparência da linguagem, remetendo ao fato de não haver sentidos prontos e únicos por trás de um texto, esperando para serem decifrados. Compreendemos que existe um processo de produção de sentidos que nega a transparência da linguagem por um observador neutro, o estudante passivo, e começamos a ver o quão importante se tornam estes conhecimentos, quando pensados no contexto do ensino e da aprendizagem da matemática.

Diante dessa aproximação com esse aporte teórico e metodológico, apoiamos nossa pesquisa na produção de narrativas, que possibilita os sujeitos "entrarem em contato com lembranças, histórias e representações sobre suas aprendizagens, discursos e rituais pedagógicos construídos no espaço escolar/acadêmico" (SOUZA; CORDEIRO, 2007, p. 47) e, portanto, por meio de problematizações e indagações, questionar modelos pedagógicos cristalizados para o ensino e aprendizagem da matemática.

O curso de Pedagogia em que desenvolvemos a pesquisa tem, em sua grade curricular, duas disciplinas referentes à matemática com 60 horas de carga horária cada uma. Na disciplina I foram discutidas questões relacionadas às 
concepções ${ }^{3}$ de matemática, à função da matemática nos anos iniciais, aos conceitos e conteúdos de número e das operações aritméticas, além de aspectos metodológicos, jogos e materiais manipuláveis. Na disciplina II foram abordados conceitos e conteúdos de geometria, frações, grandezas e medidas e estatística e probabilidade. Novamente nessa disciplina houve um diálogo com questões metodológicas, jogos e materiais manipuláveis.

A partir da leitura de duas narrativas que foram produzidas pelos estudantes de Pedagogia no início dos dois semestres letivos das disciplinas de matemática do curso de Pedagogia, respectivamente, iniciamos a análise. A primeira narrativa foi escrita com o intuito de os estudantes recordarem sobre a matemática que tiveram na Educação Básica. Para a produção da segunda narrativa, eles leram essa primeira narrativa e, assim, puderam perceber e discutir o que pensavam sobre matemática após as vivências na disciplina I.

Dos 34 estudantes matriculados na disciplina II, quatro não participaram da disciplina I e 23 produziram as duas narrativas, que serão consideradas para a análise. Os nomes dos sujeitos foram substituídos por pseudônimos com intuito de preservar suas identidades.

$\mathrm{Na}$ tentativa de aproximar e/ou distanciar as narrativas, com intuito de atingir aos objetivos propostos, criamos um quadro com três colunas: nome, principais memórias da Educação Básica e contribuições da disciplina I. Apresentamos aqui, alguns movimentos de análise a partir desse material. Para facilitar a apresentação dos dados, dividimos em dois tópicos: Memórias e matemática: relembrando algumas vivências e Contribuições na formação do pedagogo: um olhar a partir das vivências em uma disciplina.

${ }^{3}$ Compreendemos concepção como uma estrutura mental mais geral, que abrange crenças, conceitos, significados, proposições, regras, imagens mentais, preferências e gostos (THOMPSON, 1992). 


\section{Movimentos de análise}

Passamos agora a apresentar e analisar os dados das duas narrativas escritas pelos sujeitos que participaram das disciplinas referentes à matemática do curso de Pedagogia. Iniciamos discutindo as memórias da matemática e, em seguida, trazemos aspectos das contribuições das vivências na disciplina para a formação.

\subsection{Memórias e matemática: relembrando algumas vivências}

Todos nós trazemos lembranças (positivas ou negativas) do nosso processo de escolarização e, muitas vezes, essas marcas guiarão nossa vida profissional. Se pensarmos na formação dos licenciandos em Pedagogia, na qual necessitam de uma ampla formação nas mais diversas áreas do conhecimento, essas memórias não podem ser desconsideradas.

No que se refere ao professor que ensina matemática nos anos iniciais, segundo Nacarato, Mengali e Passos (2009), essas lembranças podem influenciar a constituição da identidade docente e o modelo de aula de matemática, assim, eles reproduzirão práticas dos professores que tiveram em sua escolarização.

Dessa forma, nas disciplinas de matemática foi preciso conhecer essas memórias com intuito de levar os estudantes a refletirem e a problematizarem sobre elas a fim de (des)contruir algumas concepções relacionadas ao ensino e a aprendizagem de matemática.

Dos 23 estudantes que escreveram as narrativas, 20 apontaram experiências negativas com relação a matemática, como podemos ver nos textos de Cláudia e Daniela:

Desde a infância a matemática sempre foi meu terror. $O$ método de ensino nunca foi atraente para os alunos, não despertava o interesse em aprender a matéria (Cláudia). 
Eu sempre tive problemas com a matemática, sempre fiz muitas aulas particulares, mas parece que nem sempre resolvia (Daniela).

Além disso, podemos pensar que existe uma relação entre o fracasso com a matemática e a escolha profissional na área de humanas, "como eu nunca gostei de matemática, eu acabei escolhendo um curso da área de humanas [...] (Daniela)

Essa perspectiva é apontada pelo estudo de Passos (2005) em que evidencia que muitos professores que atuam nos anos iniciais apresentam dificuldades, insegurança e mesmo aversão à matemática, procurando realizar cursos nas áreas das ciências humanas com o intuito de não ter que estudar mais essa disciplina.

Essas vivências com a matemática dificultam a sua aproximação com a área, o que poderá gerar problemas no processo de ensino como futuro docente. Nesse sentido, os desafios dos professores formadores tornam-se ainda maiores, tendo que buscar um afastamento dessas concepções e fornecer novas formas de pensar o ensino e a aprendizagem de matemática.

Dentre os discentes investigados, 22 apontaram suas aulas de matemática como tradicionais, tendo como principal suporte o livro didático. "Me lembro de algumas ocasiões que merecem menção. Sobre as aulas e o ensino, não há nada que seja importante relembrar, pois ambos ocorriam de forma mais tradicional possível: um livro didático como guia e explicações perante o quadro" (Vagner).

Bittencourt (1997) destaca que em muitas instituições o livro didático é quem determina os conteúdos a serem trabalhados. Nessa direção, as análises feitas pelo autor mostram que os conteúdos abordados estão em desacordo com a realidade dos estudantes, e tais livros reforçam esse abismo, o que pode gerar desinteresse pelo conteúdo.

Outra característica marcante na relação dos estudantes com a matemática na Educação Básica são tarefas e as avaliações escolares, que geralmente são baseadas em cópias e memorizações, sem a devida compreensão dos conceitos 
e conteúdos abordados e também sem reflexão e articulação com o cotidiano dos alunos.

As tarefas eram passadas também através do livro didático. Porém, tratavamse de tarefas inúteis pelo fato de que as respostas das mesmas se encontravam na parte final do livro e a maioria dos exercícios bastava resolver da mesma forma que o exemplo, o mesmo acontecia com as avaliações (Lara).

As tarefas e avaliações tinham formato bastante rígido, o que esperava do aluno uma única resposta (Jade).

Essa concepção vai de encontro com o papel da linguagem. Aproximamos do referencial teórico e metodológico da Análise do Discurso Francesa que busca a opacidade da linguagem, não havendo sentidos em si, naquilo que foi dito, pois a interpretação desloca sentidos, desconstruindo os efeitos do já dito em direção a outro significado.

A análise de conteúdo, como sabemos, procura extrair sentidos dos textos, respondendo à questão: o que este texto quer dizer? Diferentemente da análise de conteúdo, a Análise de Discurso considera que a linguagem não é transparente. Desse modo ela não procura atravessar o texto para encontrar um sentido do outro lado. A questão que ela coloca é: como este texto significa? (ORLANDI, 2012, p.17).

Com relação as tarefas e as avaliações, percebemos que a não transparência da linguagem não é levada em consideração. Nessas tarefas e avaliações é geralmente cobrada a reprodução idêntica ao conteúdo anteriormente ensinado, "os testes e provas servem também a mostrar que não existe o que se visa, que este será moldado pela instituição em que se inserir. É o que acontece na escola quando se ignora que o leitor real tem uma história e um posicionamento frente a outras leituras" (ALMEIDA, SORPRESO, 2010, p.19).

Associado a esse processo de decorar e reproduzir, vários estudantes apontaram dificuldades em memorizar a tabuada: "Do ensino fundamental me recordo de longas horas decorando a tabuada, sem entender a necessidade daquilo. Confesso que foi traumatizante" (Daniela). Nessa direção, percebemos a necessidade de (re)pensar as práticas em matemática com intuito de minimizar essas dificuldades, aproximando cada vez mais de um ensino que articule com a 
realidade dos alunos, "[...] talvez se estudássemos matemática de uma forma mais lúdica e relacionada ao nosso cotidiano, seria mais prazeroso e menos traumático para todos nós". (Daniela).

Apesar da maioria dos estudantes apontar imagens negativas com relação a matemática, em algum momento de sua formação inicial alguns tiveram professores que influenciaram de forma positiva, seja pela sua relação com os alunos ou por alguma metodologia diferenciada, por exemplo:

Alguns professores de matemática marcaram minha vida positivamente, acredito que pelo esforço deles em fazer com que a turma acredite que a matéria não é "chata" e impossível de ser apreendida (Lana).

Eu me lembro de uma professora que fazia de tudo para que aprendêssemos o conteúdo, ela desenhava, pegava bolinhas, figuras, jogos e etc. (Andreia).

É a partir desse contexto que buscamos nas disciplinas I e II do curso de Pedagogia meios para que os estudantes se aproximassem de práticas e de discussões que visem o prazer no aprender e no ensinar matemática, na tentativa de afastar da concepção de que matemática é "sempre difícil" e que basta decorar ou reproduzir exercícios. Buscamos fazer com que os futuros professores tivessem contato com os fundamentos da matemática e a prática da pesquisa em Educação Matemática (NACARATO; MENGALI; PASSOS, 2009).

Dessa forma, apresentamos na próxima seção, algumas contribuições das atividades e leituras que foram realizadas para pensar e problematizar o ensino e a aprendizagem da matemática.

\subsection{Contribuições na formação do pedagogo: um olhar a partir das vivências em uma disciplina}

Ao iniciarmos a disciplina II, os estudantes foram convidados a escrever uma nova narrativa, após fazerem a leitura da narrativa em que trouxeram suas memórias em relação à matemática na Educação Básica, apontando suas vivências e contribuições da disciplina I, bem como as possíveis mudanças em 
sua forma de pensar o ensino e a aprendizagem. É importante ressaltar que as dificuldades apontadas na seção anterior, foram consideradas no planejamento das duas disciplinas.

Todas as narrativas apresentaram marcas positivas da influência da disciplina I para (re)pensar as suas vivências enquanto alunos, por exemplo:

A disciplina I mostrou que podemos ensinar matemática de forma lúdica e prazerosa, abolindo a crença de que essa disciplina é difícil e complicada de ser ensinada e compreendida (Carla).

Após a disciplina entendo que o ensino de matemática que tive poderia ter sido mais enriquecido com jogos, atividades que levem ao aluno a construir o conhecimento na busca por respostas e não apenas atividades que são aplicadas para reforçar uma matéria já dada previamente (Marilia).

Podemos perceber as marcas deixadas nos discentes a partir do ingresso na disciplina I e percebemos também que um primeiro movimento foi dado rumo a uma tentativa de (re)formular a visão equivocada sobre matemática que Ihes foi apresentada na Educação Básica.

Além disso, uma característica marcante nas narrativas foi a aproximação da matemática com o prazer pelo aprender, "a disciplina I, 'reativou' o meu gosto pela matemática. Percebi que há formas interessantes de ensinar a matemática, gerando o interesse no aluno" (Milla).

Verificamos em algumas narrativas que a disciplina I foi importante, mas que ainda não promoveu mudanças significativas na visão de matemática de alguns futuros professores. Por exemplo, Tatiane comentou que "temos a matemática sempre como algo difícil, isso ainda não mudou, mas percebo outros caminhos que facilitam o despertar de interesse [pela matemática]".

Não é fácil promover mudanças nas concepções de um sujeito e, de acordo com Carneiro (2012), podemos pensar que essas transformações fazem parte de um processo que pode ter se iniciado há algum tempo e que ocorrerá apenas a partir de várias experiências de formação que provoquem, no professor, reflexões, inquietações, problematizações e questionamentos. Assim, a disciplina I pode fazer parte desse arcabouço de Tatiane que no futuro poderá levar a mudanças efetivas. 
As discussões e práticas que foram oferecidas nessa disciplina apresentaram forte influência no seu discurso, por exemplo, na maioria das narrativas os estudantes apontam a necessidade da utilização de jogos, trabalho com literatura infantil, aproximação do conteúdo com a realidade dos alunos e outras características que foram discutidas de forma direta e indireta na disciplina. "No processo de ensino de matemática o professor pode utilizar jogos, brincadeiras, materiais alternativos e outros recursos para despertar a curiosidade, o interesse e atenção dos alunos" (Daniela).

Nessa mesma perspectiva, Rute apontou que a matemática pode ser ensinada de diferentes formas, mas que o fundamental é que os alunos aprendam o conteúdo. "Existem diferentes 'maneiras' de ensinar a matemática, [mas] tem que ser de um jeito que atraia a turma toda, de forma prazerosa, divertida, mas sempre com a finalidade de fazer com que os alunos da classe aprendam $o$ conteúdo".

Carla comentou como não deve ser o ensino de matemática contrapondose de alguma forma a como aprendeu os conteúdos dessa disciplina enquanto aluna da Educação Básica, indicando que para que os conteúdos matemáticos sejam aprendidos deve-se buscar trabalhar mais próximo à realidade dos alunos. “Quando o conteúdo matemático é ensinado pelo método da memorização e da repetição de conteúdos a criança não consegue compreender e nem aprender 0 que está sendo ensinado. Ela aprende melhor quando tem oportunidade de relacionar o conteúdo abordado com o mundo a sua volta".

Nesses excertos, embora perpassados pelas vivências da disciplina I, os futuros professores trazem indícios de uma nova maneira de pensar o ensino e a aprendizagem da matemática.

A partir dessas discussões, verificamos que uma das possibilidades da produção de narrativas é fazer com que seus autores conheçam-se a si mesmos, permitindo a "tomada de consciência de significados novos e enriquecedores para a compreensão de si próprios ou do ambiente que os rodeia" (JOSSO, 2010, p. 71). Assim, a partir dessas narrativas e das vivências na disciplina I, eles podem 
ter tomado consciência das dificuldades e limitações da forma como aprenderam matemática, sendo um primeiro passo para mudarem a maneira de ver o ensino e a aprendizagem dessa disciplina.

\section{Algumas considerações}

Com os objetivos de identificar algumas memórias dos estudantes de um curso de Pedagogia relacionadas à matemática na Educação Básica e refletir sobre possíveis contribuições das disciplinas de matemática desse curso para pensar o ensino e a aprendizagem, realizamos esse estudo pautados nos referenciais da área e na produção de narrativas.

Sabemos que é necessária uma maior discussão e formação no âmbito dos cursos de Pedagogia, principalmente no que se refere à área da matemática. Vimos pelas narrativas que, de modo geral, os estudantes são fortemente marcados pelas experiências negativas que tiveram durante a Educação Básica, por exemplo. As tarefas e as avaliações escolares, a reprodução do livro didático, decorar a tabuada e um ensino que muitas vezes desconsiderava a sua realidade tiveram importante contribuição para essas experiências.

Partindo dessas premissas, nas disciplinas de matemática desse curso de Pedagogia, tentamos discutir e suprir essas dificuldades, na tentativa de propiciar uma formação mais ampla que busque uma nova maneira de pensar e promover o ensino de matemática. A partir dos discursos dos discentes, percebemos a forte influência das atividades e discussões, o que permitiu para muitos estudantes lançar um novo olhar para a disciplina de matemática. Temos indícios de que a partir dessas vivências na formação inicial, os futuros docentes poderão com maior propriedade e entendimento incentivar e promover atividades diferentes em suas aulas de matemática das que vivenciaram. 


\section{Referências}

ALMEIDA, Maria José P. M; SORPRESO, Thirza P. Memória e formação discursivas na interpretação de textos por estudantes de licenciatura. Revista Brasileira de Pesquisa em Educação em Ciências. São Paulo, v.10, n.1, p. 1-16, 2010.

BITTENCOURT, Circe M. F. Livros didáticos entre textos e imagens. In: . 0 saber histórico em sala de aula. São Paulo: Contexto, 1997.

CARNEIRO, Reginaldo F. A formação de professores dos anos iniciais em um curso de Pedagogia: contribuições das disciplinas de matemática. In: SEMINÁRIO INTERNACIONAL DE PESQUISA EM EDUCAÇÃO MATEMÁTICA, VI, 2015, Pirenópolis - GO. Anais... Pirenópolis, 2015. p. 1-11.

CARNEIRO, Reginaldo F. Processos formativos em matemática de alunas-professoras dos anos iniciais em um curso a distância de Pedagogia. 2012. 308f. Tese (Doutorado em Educação) - Centro de Educação e Ciências Humanas, Universidade Federal de São Carlos, São Carlos, 2013.

ORLANDI, Eni P. Análise de Discurso: princípios e procedimentos. Campinas: Pontes Editores, 2012.

GOMES, Maristela G. Obstáculos na aprendizagem matemática: identificação e busca de superação nos cursos de formação de professores das séries iniciais. 2006. 161f. Tese (Doutorado em Educação Científica e Tecnológica) - Universidade Federal de Santa Catarina, Florianópolis, 2006.

JOSSO, Marie-Christine. Da formação do sujeito... Ao sujeito da formação. In: NÓVOA, Antônio., FINGER, Matthias. (Org.). O método (auto)biográfico e a formação. Natal: EDUFRN, 2010. p. 59-79.

LACERDA, Sara M. O aluno concluinte do curso de Pedagogia e o ensino de matemática nas séries iniciais. 2011. 145f. Dissertação (Mestrado em Educação Matemática) Pontifícia Universidade Católica de São Paulo, São Paulo, 2011.

NACARATO, Adair M. A formação matemática das professoras das séries iniciais: a escrita de si como prática de formação. Bolema, Rio Claro, v. 23, n. 37, p. 905-930, 2010.

NACARATO, Adair M.; MENGALI, Brenda L. Da Silva; PASSOS, Cármen L. B. A matemática nos Anos Iniciais do ensino fundamental: tecendo fios do ensinar e do aprender. Belo Horizonte: Autêntica Ed., 2009. 158 p.

PASSOS, Cármen L. B. Que Geometria acontece na sala de aula? In: MIZUKAMI, Maria da Graça N., REALI, Aline M. M. R. Processos formativos da docência: conteúdos e práticas. São Carlos: EDUFSCar, 2005, p. 16-44.

SOUZA, Elizeu C.; CORDEIRO, Verbena M. R. Por entre escritas, diários e registros de formação. Presente! Revista de Educação, Salvador, n. 57, p. 45-49, 2007. 
DOI: http://dx.doi.org/10.5965/2357724X05092017001

THOMPSON, Alba G. Teachers' beliefs and conceptions: a synthesis of the research. In: GROUWS, D. A. Handbook of research on Mathematics teaching and learning. New York: Macmillan Publishing Company, 1992. p.127-146. 